\title{
Upper Ureter
}

National Cancer Institute

\section{Source}

National Cancer Institute. Upper Ureter. NCI Thesaurus. Code C160614.

The segment of the ureter that extends from the renal pelvis to the upper border of the sacrum. 